\title{
Hot Spot and Development Trend of Domestic Information Science
}

Li-ying LIN

Shijiazhuang University of Economics, Zip code: 050031

Hebei Province

China

ABSTRACT: Fundamental approach to literature metrology were introduced in this paper to make a statistical analysis on the thesis of library and information science during the period of the 11th Five-Year Plan of China with academic focus on CNKI, CSSCI collections, citation frequency, productive authors and authorities. With academic defects and deficiencies summarized from the statistical study, this paper aimed at making recommendations and references for the disciplinary development planning of library and information science, faculty construction and talent cultivation, as well as relative researching concerns.

Keywords: Bibliometric Studies, Library Information Science, Disciplinary Development, Statistical Analysis

Received: 8 May 2019, Revised 12 July 2019, Accepted 18 July

DOI: $10.6025 / \mathrm{jc} / / 2019 / 10 / 3 / 76-80$

(C) 2019 DLINE. All Rights Reserved

\section{Introduction}

The institutions of library and information science provided a key basis for academic studies and talents cultivation of this specific discipline in our country. Some knowledge of the research condition of this discipline could be gained from a statistic study of its publications, which could also help to grasp its educational trend and make recommendations and reference for the disciplinary development planning of library and information science, faculty construction and talent cultivation orientation, as well as some researching and teaching concerns etc.

\section{Statistic Foundations and Methods}

\subsection{Statistic Objects, Data Range and Analytical Items}

Notes: (1), The Information \& Resource Research Center of Wuhan University, the Research Center for Chinese Science Evaluation and the Research \& Evaluation Center for Chinese Social Science of Nanjing University couldn't be strictly distinguished and many authors have double identities, so publications of these two universities and three research institutions would be counted separately. (2), The literature \& information center of Chinese Academy of Sciences doesn't belong to the teaching and research institution, while Yunnan University only has the doctor station of archive sciences, which don't belong to the research objective of the present thesis and would not be statistically analyzed.

$76 \quad$ International Journal of Computational Linguistics Research Volume 10 Number 3 September 2019 
Statistic Objects: There were 12 universities in our countries having the doctor station of library \& information science and archive management (see chart 1). In this paper, the Renmin University of China was less than Renmin University; Shanghai Branch of Nanjing Political College was less than Shanghai Branch; Central China Normal University was less than Huazhong Normal University.

Chart 1: The universities and colleges with doctor stations of library \& information science and archive management

\begin{tabular}{|l|l|l|}
\hline $\begin{array}{l}\text { The first level doctor station of } \\
\text { library \& information science and } \\
\text { archive management }\end{array}$ & $\begin{array}{l}\text { The Pecking university } \\
\text { Wuhan University } \\
\text { Nanjing University } \\
\text { Renmin University }\end{array}$ \\
\hline The second level doctor station & Library \& information science & $\begin{array}{l}\text { Nankai University Jilin University } \\
\text { Literature \& Information Center of } \\
\text { Chinese Academy of Sciences }\end{array}$ \\
\cline { 2 - 3 } & Library \& archive science & Shanghai Branch \\
\cline { 2 - 3 } & Library science & Zhongshan University \\
\cline { 2 - 3 } & Information science & Huazhong Normal University. \\
\cline { 2 - 3 } & Archive science & Yunnan University \\
\hline
\end{tabular}

The data was collected from the papers published during 2006 to 2010 from the paper research of China Academic Journal Network Publishing Database of CNKI. The due date is August 15, 2011.

The statistic analytic items included, first, the statistical analysis of publications under the category of CNKI information \& technology; second, the statistical analysis of publications under the category of CNKI library \& information and digital library; third, the statistics of publications from Journal of Library Science in China and Journal of Information Studies; forth, the statistical analysis of documents published in the CSSCI journals; fifth, the statistical analysis of references; sixth, the statistical analysis of prolific authors and experts.

\subsection{Research Strategies and Statistical Methods}

2.2.1. The publication statistics was conducted under the category of information of technology, information of library and digital library of CNKI as search port. The time scope was from 2006-01-01 to 2010-12-31. The standard title of colleges and institutions having the specific disciplines were fuzzy research under restricted conditions, such as Department of Information Resources Management of Business School of Nankai University and School of Information Resources Management and School of Archives of Renmin University of China. Titles of other departments and institutions are supplementary search under restricted conditions, such as Business School and Department of Information Management of Nankai University etc. Cases like non-first author, non-academic paper and repeated publications of one paper will be excluded after comparison. The CSSCI literatures are categorized according to different degree. The search portal is library \& information and the research matching condition is consistent with the CNKI publication research.

2.2.2. All the publications from the twelve departments and institutions are statistically analyzed according to the CNKI research results. 1. Artificial statistics are made for the papers published in Journal of Library Science in China and Journal of Information Studies through the annual general contents of the two journals. 2. The number of papers written by on-the-job doctors and postgraduates are artificially calculated based on the author affiliation, such as Lu Yibao, the Department of Information Management of Nanjing University and the library of Huaiyin Normal University.

Summary Methods: 1. publications from the three research institutions of Wuhan University and Nanjing University are 
incorporated into corresponding schools and departments for summarization. 2. All the statistics are arranged in descending order.

\subsection{Publications Statistics and Analysis}

\subsubsection{Statistics and Analysis of Publications under the Category of Information \& Technology, CNKI}

The cross penetration of library \& information discipline and its relevant subjects demonstrated in academic papers in current days. On the one hand, the modernization of library \& information and archives becomes inevitable, and this subject has closely interrelated with computer science and network theory, becoming a key domain of research. On the other hand, in the era of new media, the science of library \& information and archives are penetrating with the filed of press and publication, providing a cross domain of this subject. This thesis will not statistically analyze the interpenetration of library \& information subject and other subjects in the respect of academic papers.

The total number of papers from Wuhan University is in approximately $34 \%$ of the overall statistics (2423/7074). Expect for the archive, under which Wuhan University ranks the forth, other categories are all led by it. In addition, its cross-field development also proceeds in a balanced way.

A careful review of the category of computer \& software and computer application in CNKI reveals that the papers are all about the application of computer in the work concerning library $\&$ information and archives, which could be seen as the modernization of library \& information and archive. The total number of this category is just second to the library $\&$ information, implying that this aspect of research is attached great importance by the universities, and reflecting the enhancement and development trend of modernized research of library \& information and archive in our country from one side. The number of this kind of paper in Renmin University, Huazhong Normal University and Shanghai Branch is even greater than that of library \& information; the paper of this category in Jilin University also accounts for 39\% (152/389), all displaying a strong sense of research modernization.

\subsubsection{Classification and Statistical Analysis of Publications under the Category of Library \& Information and Digital Library} The established search strategies are employed for the category of information \& technology, library \& information and digital library. Since there is no further classification for this category in CNKI, we couldn't categorize and analyze all papers, and as a result, this thesis saves and prints the searching results with the layout provided by CNKI. All the papers are artificially classified according to the chart three based on the topic to discuss.

\subsubsection{Classification Basis}

The designing of the classification and its contents refers to the traditional classification method of the library \& information and the fundamental ideas of literatures combined with the paper themes of nine departments.

\subsubsection{Statistical Analysis}

The research condition of each institution during the $11^{\text {th }}$ Five-year-Plan of China. The papers of different sorts are of balanced quantity, indicating that the general research of library \& information focuses on comprehensiveness.

The number of papers published by Wuhan University assumes the absolute advantage, contributing 1/3 of the entire number (1216/3238). And these publications cover each area of library \& information studies, highlighting its leading position in the research and talents cultivation of this field in our country. For the introductory papers, there are some words of high frequency like intellectual management, intellectual property, information security, vulnerable group etc., and in addition, many researching results are also impressing in the aspect of metric analysis and evaluation, digital library theories, ancient book studies and modern library history.

Among the overall publications in Nanjing University, there are 35\% (203/574) of these papers are about metrics and evaluation, which is a high proportion showing that the Research and Evaluation Center of Chinese Social Science in Nanjing University plays a key role in the education and research of library \& information filed in this university. Besides, there are also many works of book reviews with both high quality and quantity in the field of library policies, information processing of digital library, reading therapy in reading theories and so on.

\section{Other Statistic Analysis}

\subsection{Statistic Analysis of CSSCI Literatures}

CSSCI collection is an important index to evaluate the quality of journal papers in the field of social science of our country. If the

78 International Journal of Computational Linguistics Research Volume 10 Number 3 September 2019


publication quantity of the two journals reflects the ability of publication on high level journals as a "point" of quality measurement, the literatures included in CSSCI could indicate the comparison of quality from "side". For the absolute number compared with the chart four, other orderings almost stay the same except for a tiny change for Jilin University and the Central China Normal University. As for the relative number, every university assumes a high collection proportion of CSSCI-all of them (except a little lower proportion for Shanghai Branch) have the proportion over $80 \%$, and some even higher than $90 \%$ like Nankai University, Jilin University, Pecking University and Renmin University. And nearly $1 / 3$ of the papers in this field collected by CSSCI every year come from these universities, showing the evident advantage of the quality of publications from schools and universities with doctoral stations.

\subsection{Statistic Analysis of Papers with High Citation Rate}

From the perspective of thesis topic, we could find the highlight of library $\&$ information research during the $11^{\text {th }}$ Five-Year-Plan of China, among which there are 3 articles concerning the role of library in the harmonious society, written by several senior scholars. These articles reflect a strong sense of times, thus receiving much attention from the scholars and are cited with high frequency. These are 6 articles about methods and evaluation of service theories such as library intellectual service, personalized service, and general service and so on, thus we can see that library serving the society, which is spoken highly of, has received a lot attention and emphasis from the academic field during the period of $11^{\text {th }}$ Five-Year-Plan. The researchers have deepened it to various levels. The construction of other information principles and systems all have great guiding value on the macro level as well as classic reference value. In addition, there are many other research highlights like intellectual management, intellectual map, business outsourcing, database construction, search engine etc., which share a common feature of research cutting-edge. Therefore, these articles have a rate of citation. Under the impact of half-life pattern of paper citation, the twenty articles are all published prior to the year 2008. And it is impossible to list the quality papers released after 2008 based on the present citation rate.

\subsection{Statistical Analysis of Prolific Authors}

There are 46 authors who have published over 10 papers. In the team of prolific authors, there are 15 out of 46 people from Wuhan University, accounting for 33\% of the total number, nine from Pecking University, seven from Nanjing University, six from Zhongshan University, five from Nankai University, two from Jilin University, one from Central China Normal University, one from Shanghai Branch and Renmin University has 12 authors having published over 10 papers of archive science, which will not be listed here one by one. We could see some familiar names, which there are totally 38 acknowledged scholars in the field of library \& information in our country. For several decades, they have contributed to the prosperity of our library \& information business through diligent research and constant writings.

\subsection{Analysis of Dominant Experts}

Based on the results of publication classification results, a specialist distribution chart is made with references of relevant information of these authors. And reflects that Wuhan University performs well both in the field occupied by specialists and the structure of teaching \& research group. Nanjing University doesn't have many dominant experts, but they are middle-aged backbones who are energetic. From the overall point of view, the distribution of experts in the field of library \& information science is not balanced in disciplinary field and structure of region and age. And the problems are prominent in several aspects.

\section{Comments}

\subsection{Strengthening the Macro Planning of Discipline Construction}

The science of library \& information and archive science share some common ground, for both of them belong to the class-one discipline. On the macro-level, equal importance should be attached to the development of the three class-two disciplines. For instance, Pecking University should value both the library science and information science, and the same applies for Nanjing University in the field of library science and archive science. The construction of key class-two disciplines could only be supported with stronger momentum when they are developed in coordination.

\subsection{Strengthening the Construction of Teaching \& Research Faculty}

The phenomenon can't be ignored that there is an aging trend in dominant experts in the area of library \& information science. The problem of seniority in academic research still persists in the field of library \& information in our country, which gives priority to authors instead of articles. Some schools and departments even make teachers writing papers for others, hindering the development of young talents. Each university should give priority to the level construction of teaching \& research faculty. Some effective measures are required to cultivate the new researchers with various approaches such as to study abroad, to fund

International Journal of Computational Linguistics Research Volume 10 Number 3 September 201979 
the scientific research, to offer academic rewards etc. so as to favor the youth, or some schools and departments will lack new qualified successors. For many institutions with a lack of dominant experts, the disciplinary construction will be hard to develop and it is even likely that there will be no successors.

The science of library \& information contains the creation of information and knowledge. There is little human-oriented content in communication \& evaluation, selection \& interview, organization \& description, reserve \& retrieval, saving, analysis, interpretation, appraisal, composition, transmission and management[5]. This phenomenon could rather be understood as a kind of defection than the transformation of library \& information research. The research orientation of dominant experts from institutions with doctoral stations to a large extent leads the direction of domestic research on library \& information. With technological development in present days, people -oriented awareness as well as service-oriented research on readers should be enhanced.

\section{References}

[1] Xudong, Li. (2010). Science of Library \& Archive, doctoral station [2010-04-10]. http: //wenku.baidu.com/view/88880879168 884868762d697.html.

[2] Zhiping, Qiu., Jinda, Ding., Chunlei, Zhou. (2009). 1999-2008. Empirical Study on the Library Science of Our Country (1) Journal of Library Science in China. 2009 (9) 72-79.

[3] Xinning, Su. (2007). Report of the Academic Influence of Humanity \& Social Science. Beijing: China Social Sciences Press, 2007, 1069-1072.

[4] Jiazhen, Liu., Wangao, Cheng. (2008). Analysis of Chinese Ancient Book Protection and Strategic Research, Journal of Library Science in China. 2008 (4) 8-13.

[5] Lancaster. Free Survival, translated by Wang Xing. Journal of Library Science in China. 2011 (37) 19-23.

[6] Wufang, Qiu. (2008). Empirical Study on Further Development of Chinese Library Science, Journal of Library Science in China. 2008 (1) 16-21.

[7] Yu, Liu., Jiyuan, Ye., Anlin, Yuan. (2009). Study on the Lack of Empirical Research of Chinese Library Science, Journal of Library Science in China. 2009 (4) 20-24, 30.

[8] Wufang, Qiu. (2009). Several Issues on Improving Research Accuracy-Integrating Theory of Library Science with Practice, Library, 2009 (3) 10-12, 15. 